\title{
Epigallocatechin Gallate Does Not Accelerate the Early Phase of Liver Regeneration After Partial Hepatectomy in Rats
}

\author{
Vojtěch Mezera $\cdot$ Otto Kučera $\cdot$ Alena Moravcová $\cdot$ \\ Eva Peterová · Zuzana Červinková
}

Received: 1 July 2013/Accepted: 15 November 2013/Published online: 8 December 2013

(C) The Author(s) 2013. This article is published with open access at Springerlink.com

\begin{abstract}
Background Two-thirds partial hepatectomy ( $\mathrm{PHx})$ is an established model for the study of liver regeneration after resection. This process is accompanied by oxidative stress. Aims In our study, we tested the effect of epigallocatechin gallate (EGCG), a green tea antioxidant, on the early phase of liver regeneration after PHx.

Methods Male Wistar rats were divided into five groups: (I) laparotomy + water for intraperitoneal injections, (II) laparotomy + EGCG $50 \mathrm{mg} / \mathrm{kg}$ body weight, (III) PHx + water for injections, (IV) PHx + EGCG $20 \mathrm{mg} / \mathrm{kg}$ and (V) PHx + EGCG $50 \mathrm{mg} / \mathrm{kg}$, for 3 consecutive days. The rats were killed $24 \mathrm{~h}$ after surgery. Biochemical analysis of rat sera was performed. Histological samples were stained with hematoxylin \& eosin and bromodeoxyuridine (BrdU). In hepatectomized rats, we also measured plasma malondialdehyde, tissue malondialdehyde, glutathione and cytokines levels, the activity of caspases $3 / 7$, expression of
\end{abstract}

V. Mezera $(\varangle) \cdot$ O. Kučera · A. Moravcová · Z. Červinková Department of Physiology, Faculty of Medicine in Hradec Kralove, Charles University in Prague, Simkova 870, 50038 Hradec Kralove 1, Czech Republic

e-mail: mezev5ar@1fhk.cuni.cz

O. Kučera

e-mail: kucerao@lfhk.cuni.cz

A. Moravcová

e-mail: moravca2@1fhk.cuni.cz

Z. Červinková

e-mail: wolff@lfhk.cuni.cz

E. Peterová

Department of Biochemistry, Faculty of Medicine in Hradec

Kralove, Charles University in Prague, Hradec Kralove 1, Czech Republic

e-mail: peterovae@lfhk.cuni.cz
Nqo-1 and HO-1 genes at the mRNA level, and expression of p21, p-p27 and p-p53 genes at the protein level.

Results We observed lower accumulation of BrdU in group V when compared to groups III and IV. The activity of caspases 3/7 and expression of p-p53 were lower in group V than in groups III and IV. Tissue levels of IL-6 were lower in group V when compared to group III. Significant differences were not noted in other parameters.

Conclusions Administration of EGCG did not stimulate early phase liver regeneration in rats after PHx. There was even lower DNA synthesis in the group treated with a high dose of EGCG.

Keywords Antioxidants - Epigallocatechin gallate · Hepatectomy · Liver regeneration · Oxidative stress

$\begin{array}{llll}\text { Abbreviations } & & \\ \text { AI } & \text { Water for injections } & & \\ \text { ALT } & \text { Alanine aminotransferase } & & \\ \text { ALP } & \text { Alkaline phosphatase } & & \\ \text { AST } & \text { Aspartate aminotransferase } & & \\ \text { BrdU } & \text { 5-Bromo-2-deoxyuridine } & & \\ \text { EGCG } & \text { Epigallocatechin gallate } & & \\ \text { EGCG20 } & \begin{array}{l}\text { Epigallocatechin gallate } 20 \mathrm{mg} / \mathrm{kg} \\ \text { weight }\end{array} & \text { body } \\ \text { EGCG50 } & \text { Epigallocatechin gallate } 50 \mathrm{mg} / \mathrm{kg} & \text { body } \\ & \text { weight } & \\ \text { GSH } & \text { Glutathione (reduced form) } & & \\ \text { GSSG } & \text { Glutathione (oxidized form) } & & \\ \text { HO-1 } & \text { Heme oxygenase-1 } & \\ \text { HRR } & \text { Hepatic regeneration rate [25] } & \\ \text { IL-6 } & \text { Interleukin-6 } & \\ \text { LAP } & \text { Laparotomy } & \\ \text { LRR } & \text { Liver regeneration rate [26] } \\ \text { MDA } & \text { Malondialdehyde } & \\ & & & \end{array}$


Nqo-1 NAD(P)H-quinone-oxidoreductase

Nrf2-2 NF-E2-related factor 2

PHx Two-thirds partial hepatectomy

TGF- $\beta 1$ Transforming growth factor beta1

TNF- $\alpha \quad$ Tumor necrosis factor alpha

\section{Introduction}

Liver resection is a surgical procedure performed for a variety of malignant and benign focal liver lesions. It is one of the few methods that gives the patient a chance for complete recovery. This is in both primary liver tumors, especially hepatocellular carcinoma [1], and secondary tumors, notably liver metastases from colorectal carcinoma [2].

Vascular occlusion, used during liver resection to prevent hemorrhage, causes ischemia-reperfusion injury. Reperfusion of the liver enhances cell injury by oxidative stress and an inflammatory reaction [3]. In addition, liver regeneration itself was found to be a state of increased oxidative stress $[4,5]$. Some surgical procedures for preventing the ischemia-reperfusion injury have already found their way into clinical practice [3], whereas possible pharmacological approaches remain limited. This is because no decrease in mortality, incidence of liver failure or perioperative morbidity was found [6]. Two-thirds partial hepatectomy (PHx), carried out on small laboratory animals, is a well-established model for studying of liver regeneration [7].

Excessive oxidative stress observed in mice after knockout of a key transcription factor for endogenous antioxidative enzymes led to significant diminution of liver regeneration after PHx [8]. This transcription factor, NFE2-related factor 2 (Nrf2), is an upstream regulator of various antioxidative proteins and xenobiotic-metabolizing enzymes, particularly glutathione- $S$-transferase, NAD(P)Hquinone-oxidoreductase (Nqo-1), superoxide-dismutase, glutathione-peroxidase, heme oxygenase-1 (HO-1), catalase and others [8-10].

Protection against oxidative stress may enhance liver regeneration after resection, as shown in a study using vitamins $\mathrm{C}$ and $\mathrm{E}$ [11]. Aside from these directly acting antioxidants, which after oxidation can act as pro-oxidants, indirect antioxidants exist. These are able to activate the aforementioned transcription factor Nrf2 and subsequently many cytoprotective proteins $[9,10]$. The indirectly acting antioxidants have very low prooxidative effects [12].

One of these is (-)-epigallocatechin-3-gallate (EGCG), a polyphenolic antioxidant from green tea. Besides this effect, EGCG also acts as a direct antioxidant because of the presence of phenolic groups that are sensitive to oxidation and can generate quinone [9, 13]. EGCG is the most abundant of the green tea catechins [14]. Its protective role was found in a model of acute toxic liver injury [15], chronic toxic liver injury [16, 17], non-alcoholic steatosis and steatohepatitis [18-20], and hepatic ischemia-reperfusion injury [18, 21]. EGCG was also able to ameliorate experimental diabetes mellitus by downregulation of genes for gluconeogenesis and synthesis of fatty acids, triacylglycerols and cholesterol [22, 23]. The effect of EGCG on liver regeneration after PHx has not been tested yet.

In our study, we tested the effect of EGCG in the early phase of liver regeneration after PHx in rats. Since the highest rate of DNA synthesis is in hepatocytes $24 \mathrm{~h}$ after PHx [24], we decided to investigate the regenerative response in this particular interval. We also focused on the monitoring of possible changes in relevant signaling pathways.

\section{Methods}

\section{Chemicals}

Unless otherwise stated, BrdU (5-bromo-2-deoxyuridine) and other chemicals used were all of analytical grade and had been purchased from Sigma-Aldrich (St. Louis, MO, USA). The kit for determination of caspase 3/7 activities was obtained from Promega (Madison, WI, USA). Mouse monoclonal anti-BrdU antibody had been obtained from DAKO (Glostrup, Denmark) and secondary anti-mouse antibody from Jackson ImmunoResearch Laboratories (West Grove, PA, USA).

Mouse anti- $\beta$-actin antibodies and rabbit anti-p21 CIP1 were purchased from Sigma-Aldrich, rabbit p27 Kip1 and rabbit phospho-p53 (Ser15) from Cell Signaling (Beverly, MA, USA), mouse Bcl-2 antibody (C-2) from Santa Cruz Biotechnology (Dallas, TX, USA), secondary goat antirabbit IgG from Sigma-Aldrich and secondary goat antimouse IgG from Santa Cruz Biotechnology.

\section{Experimental Design}

Male Wistar rats (BioTest, Konárovice, Czech Republic) with initial weight of $248 \pm 13 \mathrm{~g}$ were used throughout the study. The rats were housed at $23 \pm 1{ }^{\circ} \mathrm{C}, 55 \pm 10 \%$ humidity, air exchange 12-14 times/h and $12 \mathrm{~h}$ light-dark cycles. The animals had free access to tap water and were fed the standard pelleted diet ST-1 ad libitum (Velas, Lysá nad Labem, Czech Republic). In accordance with Czech legislation, all animals received care according to the guidelines set out by the Institutional Animal Use and Care 
Committee of the Faculty of Medicine of Hradec Králové, and this committee approved our study.

The animals were selected for laparotomy (LAP, sham operation) or 2/3 partial hepatectomy (PHx) under ether anesthesia [7]. Water for injections (AI) or EGCG in a dose of 20 or $50 \mathrm{mg} / \mathrm{kg}$ body weight was administered intraperitoneally for 3 consecutive days (regimen according to [15]), with the third dose administered immediately after the operation. The animals were divided into following five groups:

I-AI + LAP: water for injections and laparotomy, $n=6$;

II-EGCG50 + LAP: EGCG $50 \mathrm{mg} / \mathrm{kg}$ and laparotomy, $n=6$;

III-AI + PHx: water for injections and PHx, $n=6$;

IV-EGCG20 + PHx: EGCG $20 \mathrm{mg} / \mathrm{kg}$ and PHx, $n=6$;

V-EGCG50 + PHx: EGCG $50 \mathrm{mg} / \mathrm{kg}$ and PHx, $n=6$.

The animals were killed under general general anesthesia by exsanguination $24 \mathrm{~h}$ after the operation, i.e., on the 4 th day of the experiment. BrdU for detection of DNA synthesis was administered at a dose of $50 \mathrm{mg} / \mathrm{kg}$ intraperitoneally $1 \mathrm{~h}$ before sacrificing. Blood and liver samples were immediately frozen in liquid nitrogen and stored at $-80{ }^{\circ} \mathrm{C}$ until analysis. Resected liver from the 3rd day and the remnant on the 4th day were weighed and liver growth was calculated according to formulas from the literature $[25,26]$.

\section{Serum Biochemical Measurements}

Serum concentrations of glucose, total and conjugated bilirubin, activities of alanine aminotransferase (ALT), aspartate aminotransferase (AST) and alkaline phosphatase (ALP) of all animals were measured in the Department of Clinical Biochemistry and Diagnostics, University Hospital in Hradec Králové. In the hepatectomized groups (groups III, IV, V), plasmatic levels of malondialdehyde (MDA) were also measured.

\section{Determination of GSH and GSSG}

After adding the liver homogenate to cold $10 \%$ metaphosphoric acid, mixing and centrifuging $(20,000 \times g$, 10 min., $4^{\circ} \mathrm{C}$ ), glutathione in the supernatant was analyzed by Hissin's fluorimetric method [27] modified by Roušar [28]. Briefly, GSH was exposed to orthophthalaldehyde in hydrogenphosphate buffer, and the fluorimetric detection was carried out $(\lambda E x=340 \mathrm{~nm}, \lambda E m=420 \mathrm{~nm})$. GSSG was assessed after alkaline hydrolysis in the same way as GSH.
Determination of Liver Tissue Cytokines and TBARS

The protein content in the sample was determined after homogenization in RIPA buffer and spinning $(10,000 \times g)$ by the Bradford method [29] using bovine serum albumin as a standard. Afterwards, levels of liver TNF- $\alpha$ in the supernatant were measured using the ELISA method. Rat TNF-alpha Platinum ELISA, Rat IL-1 beta Platinum ELISA and Rat TGF-beta1 Platinum ELISA kits were purchased from eBioscience (San Diego, CA, USA).

Lipid peroxidation in liver supernatants from the homogenates was determined according to Ohkawa et al. [30], i.e., by the assessment of thio barbituric acid reactive substances (TBARS).

Determination of Caspase-3/7 Activity in Liver Homogenate

Activity of executive caspases was measured using the Caspase-Glo ${ }^{\mathrm{TM}}$ 3/7 kit. Briefly, after homogenization according to Liu et al. [31], the tissues were centrifuged and samples adjusted to contain the same amount of protein [29]. The samples were incubated for 1 and $2 \mathrm{~h}$ with Caspase-Glo ${ }^{\mathrm{TM}}$ reagent (contains substrate for caspases 3/7), and the emitted luminescence was measured using the TECAN Infinite M200.

Determination of p21, p-p27, p-p53, and Bcl-2 Expression

Expression of p21, p-p27 and p-p53 genes at the protein level was estimated using the Western blot method as described previously [32]. After homogenization [31] and quantification of protein content [29], the lysates containing an equal amount of protein $(10 \mu \mathrm{g})$ were subjected to SDS-PAGE using gradient gel NuPAGE ${ }^{\circledR}$ Novex $^{\circledR}$ Bis-Tris Mini gels 4-12\% (Life Technologies, Carlsbad, CA, USA) and transferred to a cellulose nitrate membrane (Bio-Rad Laboratories, Hercules, CA, USA). The membranes were incubated with primary rabbit antibodies at $4{ }^{\circ} \mathrm{C}$ overnight and with secondary antibody goat anti-rabbit IgG for $2 \mathrm{~h}$. Proteins were visualized using a chemiluminescence detection kit (Roche, Penzberg, Germany) and autoradiographic film (Foma, Hradec Kralove, Czech Republic). To confirm equal protein loading, each membrane was reprobed and reincubated to detect $\beta$-actin. The preparation differed for Bcl-2 protein, where we used a more concentrated homogenate of liver tissue in RIPA buffer.

Determination of HO-1 and Nqo-1 Gene Expression

Gene expression was examined as previously described [33], with the exception that total RNA from liver tissue was isolated by phenol-chloroform extraction using the 
RNA Blue kit (TOP-Bio, Prague, Czech Republic). TaqMan Fast Universal PCR Master Mix and pre-designed TaqMan Gene Expression Assay kits were from Life Technologies (Carlsbad, CA, USA), and primers and probe were purchased from Generi Biotech (Hradec Králové, Czech Republic). Glyceraldehyde-3-phosphate dehydrogenase was used as reference for normalizing the data.

\section{Liver Histology, Incorporation of Bromodeoxyuridine}

After the rats had been killed, liver samples were immediately fixed by immersion in $4 \%$ neutral formaldehyde. Paraffin sections were stained with hematoxylin \& eosin and checked for the presence of steatosis and/or inflammation. Furthermore, apoptosis was assessed according to [34], i.e., the number of apoptotic bodies per visual filed was calculated in hematoxylin \& eosin-stained samples. The pathologist evaluating the samples was blinded to the study.

The immunohistochemical analysis was made on paraffin sections of the liver tissue as described previously [35]. Briefly, the paraffin sections were incubated with primary mouse anti-BrdU monoclonal antibody, then with biotinylated anti-mouse secondary antibody and subsequently with a streptavidin conjugate of peroxidase (Dako, Glostrup, Denmark). Visualization of bound antibody was performed using 3,3'-diaminobenzidine-tetrahydrochloride and hydrogen peroxide. BrdU incorporation was determined by counting of positively stained hepatocyte nuclei in nine representative microscope fields $(\times 100$ magnification) using an Olympus IX51 microscope and quantified using a computer-aided image analysis system NIS-Elements AR 2.30 (Nikon, Lewisville, TX, USA).

\section{Statistical Analysis}

The results are expressed as the mean $\pm \mathrm{SD}$. Analyses were performed using Graph-Pad Prism 4.03 software (Graph Pad Software, San Diego, CA, USA). First, normality was tested by Kolmogorov-Smirnov test. In normal data, comparisons were made among the groups using ANOVA followed by Tukey-Kramer's post hoc test. In the case of non-Gaussian distribution, non-parametric KruskalWallis tests and Dunn's post hoc test were used. $p<0.05$ was considered statistically significant.

\section{Results}

Animals, Body and Liver Weight

During our experiment all animals survived until the sacrifice. One animal from the EGCG50 + PHx group had a surgical complication (hemoperitoneum) and was excluded

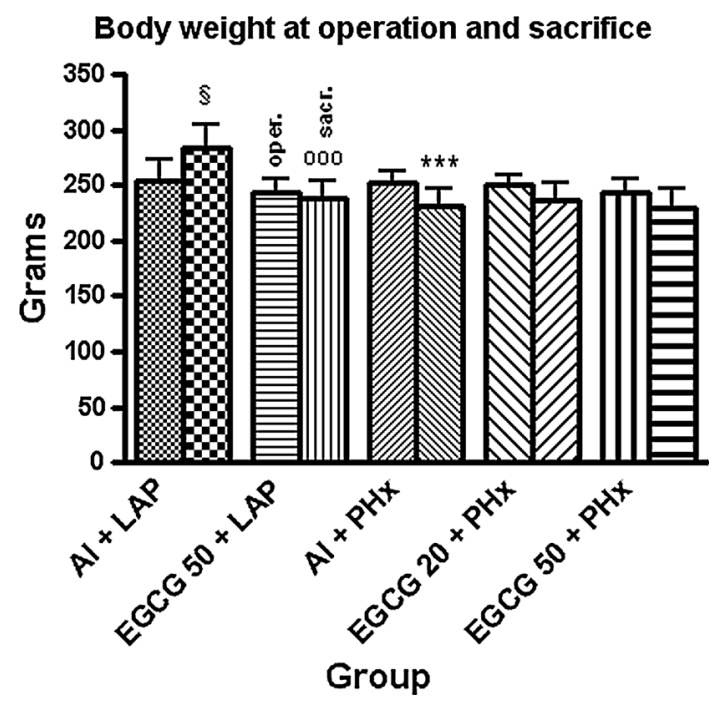

Fig. 1 Body weight of experimental animals at operation (day 1) and at sacrifice (day 2). $\S, \S \S, \S \S \S$ When comparing the same group at sacrifice and at operation. ${ }^{\circ},{ }^{\circ},{ }^{\circ}$ When comparing the EGC$\mathrm{G} 50+\mathrm{LAP}$ group with the $\mathrm{AI}+\mathrm{LAP}$ group; *, **, *** when compared to laparotomized animals (AI + PHx vs. AI + LAP; EGCG20 + PHx vs. EGCG50 + LAP; EGCG50 + PHx vs. EGCG50 + LAP), $p<0.05 ; p<0.01 ; p<0.001$, respectively

Table 1 Indices of liver regeneration

\begin{tabular}{lrlrl}
\hline & AI + PHx & $\begin{array}{l}\text { EGCG } \\
20+\text { PHx }\end{array}$ & $\begin{array}{l}\text { EGCG } \\
50+\text { PHx }\end{array}$ & $p$ value \\
\hline HRR (\%) & $9.5 \pm 4$ & $13.5 \pm 6$ & $8.9 \pm 10$ & ns \\
LRR (\%) & $23.3 \pm 8$ & $29.9 \pm 9$ & $18.1 \pm 25$ & ns \\
\hline
\end{tabular}

$\operatorname{HRR}(\%)=(C-(A-B)) / A \times 100$ (Murata [26])

$\operatorname{LRR}(\%)=(C-(A-B)) / C \times 100($ Selzner [25])

$A$ estimated total liver weight at $\mathrm{PHx}, B$ excised liver weight, $C$ weight of regenerated liver at sacrifice

from further analysis. In group I (AI + LAP) the body weight rose after the operation $(p<0.05)$; in all other groups, there was a non-significant trend to decline in body weight after the operation. Body weight at operation did not differ among groups; however, body weight was higher at sacrifice in the AI + LAP group when compared to the EGCG50 + LAP and AI + PHx groups $(p<0.001)$ (Fig. 1).

Among hepatectomized groups (III, IV, V), the calculated indices of liver regeneration appeared highest in the EGCG20 + PHx group; however, due to high variability the differences were not statistically significant (Table 1).

Histological Findings, Incorporation of BrdU

In hematoxylin \& eosin staining from the caudate lobe, distinct lipid accumulation was visible in the hepatectomized groups (III, IV, V); this is consistent with published 
Fig. 2 a DNA synthesis estimated by BrdU incorporation. *,**, *** When compared to laparotomized animals (AI + PHx vs. $\mathrm{AI}+\mathrm{LAP}$ : EGCG20 + PHx vs. EGCG50 + LAP; EGCG50 + PHx vs. EGCG50 + LAP); ${ }^{+,}++$,

${ }^{+++}$when compared to the $\mathrm{AI}+\mathrm{PHx}$ group; ${ }^{\times, \times \times}$, $\times \times \times$ when compared to the EGCG20 + PHx group, $p<0.05 ; p<0.01 ; p<0.001$, respectively. b Laparotomized groups: only sporadic BrdUpositive cells. c Group III $(\mathrm{AI}+\mathrm{PHx})$ : numerous BrdUpositive cells. d Group V (EGCG50 + PHx): numerous BrdU-positive cells, but less than in groups III and IV. Note that the positive nuclei are mostly in periportal areas. e Apoptotic bodies. *, **, *** When compared to laparotomized animals (AI + PHx vs. AI + LAP; EGCG20 + PHx vs. EGCG50 + LAP; EGCG50 + PHx vs. EGCG50 + LAP)

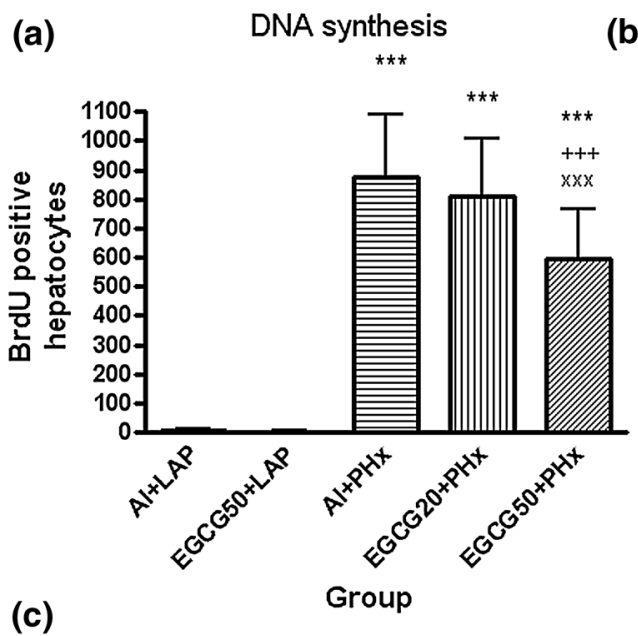

(b)

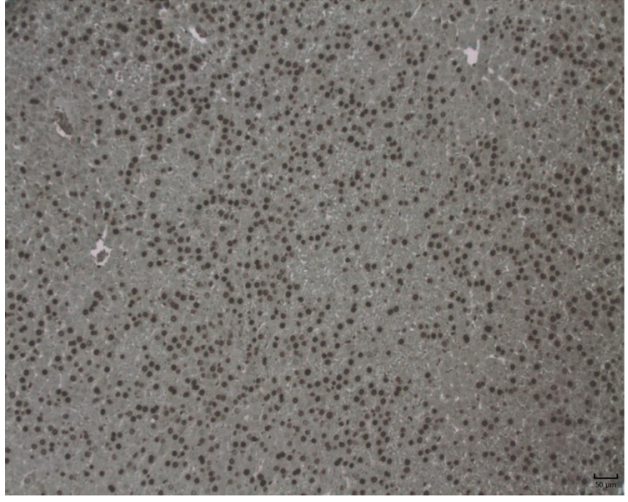

(d)
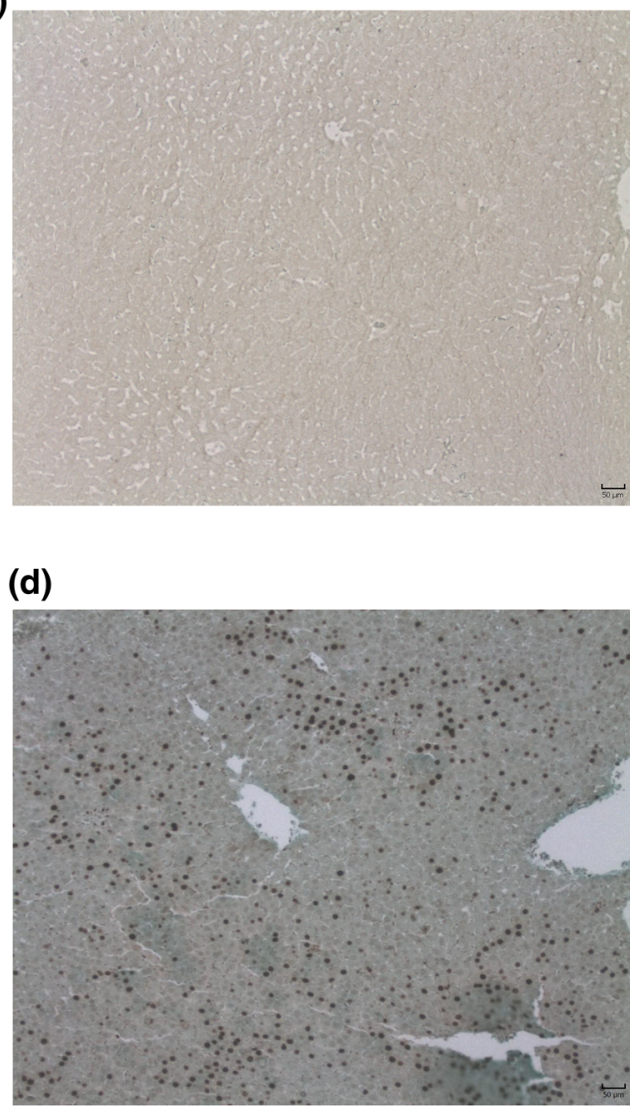

\section{(e) Apoptotic bodies in H\&E staining}

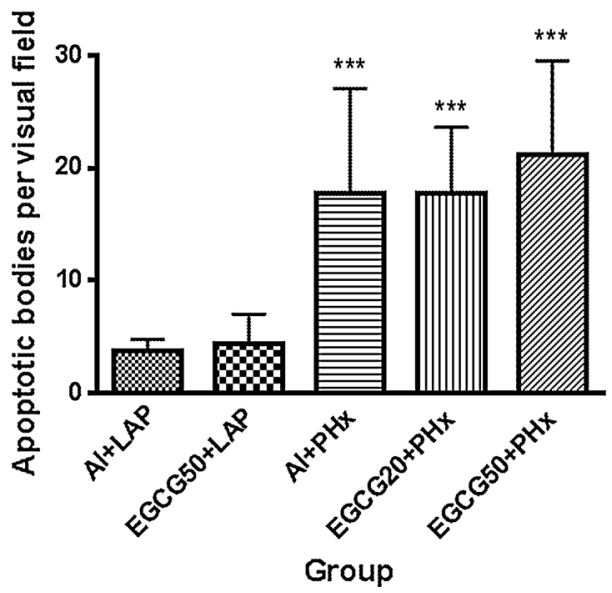

data [36]. In addition, there was vacuolation of the cytoplasm in peripherally located hepatocytes in the hepatectomized groups and sporadically occurring pyknotic nuclei. In the center of the lobe, sparse hepatocytes with granular eosinophilic cytoplasm occurred. We did not observe signs of pronounced inflammatory infiltration in any of the rats. The number of apoptotic bodies was significantly higher in the hepatectomized groups (III, IV, V) compared to the laparotomized groups (I, II). The apoptotic bodies were mostly noticed around the central veins. The laparotomized groups did not differ from one another in apoptotic body count; we did not observe differences among the hepatectomized animals either (Fig. 2e).

Immunohistochemical staining for incorporated BrdU showed only sporadic positive hepatocytes in the laparotomized groups (I, II); there was high positivity in the hepatectomized groups (III, IV, V). We observed no difference between groups III and IV; however, the count of BrdU-positive cells in the EGCG50 + PHx group was lower when compared to the $\mathrm{AI}+\mathrm{PHx}$ and 
Table 2 Serum biochemistry

\begin{tabular}{lcccccc}
\hline & AI + LAP & EGCG 50 + LAP & AI + PHx & EGCG 20 + PHx & EGCG 50+ PHx & $p$ value \\
\hline Glycemia $(\mathrm{mmol} / \mathrm{l})$ & $7.01 \pm 0.61$ & $10.49 \pm 0.28^{\circ}$ & $7.97 \pm 0.57$ & $8.9 \pm 0.69^{*}$ & $8.71 \pm 0.75^{*}$ & $<0.001$ \\
ALT $(\mu \mathrm{kat} / \mathrm{l})$ & $1.01 \pm 0.57$ & $0.64 \pm 0.06$ & $4.08 \pm 4.76$ & $2.7 \pm 1.38^{* *}$ & $5.44 \pm 4.95^{* *}$ & $<0.01$ \\
AST $(\mu \mathrm{kat} / \mathrm{l})$ & $3.2 \pm 1.99$ & $1.89 \pm 0.37$ & $7.05 \pm 6.34$ & $6.33 \pm 2.57^{* *}$ & $9.92 \pm 8.20^{* *}$ & $<0.01$ \\
ALP $(\mu \mathrm{kat} / \mathrm{l})$ & $2.4 \pm 0.45$ & $2.57 \pm 0.32$ & $7.08 \pm 1.11^{* * *}$ & $6.8 \pm 1.29 * * *$ & $6.61 \pm 1.39^{* * *}$ & $<0.001$ \\
Bilirubin total $(\mu \mathrm{mol} / \mathrm{l})$ & $2.0 \pm 0.0$ & $3.0 \pm 0.0$ & $4.0 \pm 1.55^{*}$ & $3.5 \pm 0.55$ & $5.6 \pm 2.19$ & $<0.05$ \\
Bilirubin conj. $(\mu \mathrm{mol} / \mathrm{l})$ & $1.83 \pm 0.41$ & $2.0 \pm 0.0$ & $2.6 \pm 0.89$ & $2.17 \pm 0.41$ & $4.2 \pm 2.28^{*}$ & $<0.05$
\end{tabular}

$\circ,{ }^{\circ \circ},{ }^{\circ \circ}$ When comparing the EGCG50 + LAP with the AI + LAP group

$*, * *, * * *$ When compared to laparotomized animals (AI + PHx vs. AI + LAP; EGCG20 + PHx vs. EGCG50 + LAP; EGCG50 + PHx vs. EGCG50 + LAP), $p<0.05 ; p<0.01 ; p<0.001$, respectively

EGCG20 + PHx groups ( $p<0.001$ for both comparisons) (Fig. 2a-d). BrdU positivity and thus DNA synthesis were noticed mostly in the periportal areas (Fig. 2c-d).

Serum Biochemical Characteristics

Serum glycemia was higher in group II (EGCG50 + LAP) when compared to group I (AI + LAP). There was a trend towards hyperglycemia even at a dose of $20 \mathrm{mg} / \mathrm{kg}$ when comparing group IV (EGCG20 + PHx) with group III $(\mathrm{AI}+\mathrm{PHx})$. In addition, we observed lower glycemia in the hepatectomized groups treated with EGCG when compared to the EGCG50 + LAP group.

Alanine aminotransferase and aspartate aminotransferase activity was higher in hepatectomized animals, but the statistical significance was present only when comparing EGCG20 + PHx and EGCG50 + PHx with EGCG50 + LAP. Furthermore, the ALT and AST activity was somewhat lower in the EGCG20 + PHx than in the AI + PHx group, but this difference did not reach statistical significance. Alkaline phosphatase activity was higher in all hepatectomized groups when compared to the laparotomized groups.

Total bilirubin was higher in the EGCG50 + LAP group than in the AI + LAP group, and in the hepatectomized than in the laparotomized groups; however, a significant difference was observed only when comparing the $\mathrm{AI}+\mathrm{PHx}$ with the AI + LAP groups. Conjugated bilirubin was higher in the hepatectomized than in the laparotomized groups, reaching significance only when comparing the EGCG50 + PHx with the EGCG50 + LAP group. Both total and conjugated bilirubin reached their highest values in the EGCG50 + PHx group; however, the differences among hepatectomized groups were not statistically significant (Table 2).

Tissue Cytokines TNF- $\alpha$, IL- 6 , and TGF- $\beta$ : Markers of Oxidative Stress

We observed an insignificant trend of lower TNF- $\alpha$ in hepatectomized groups treated with EGCG when compared

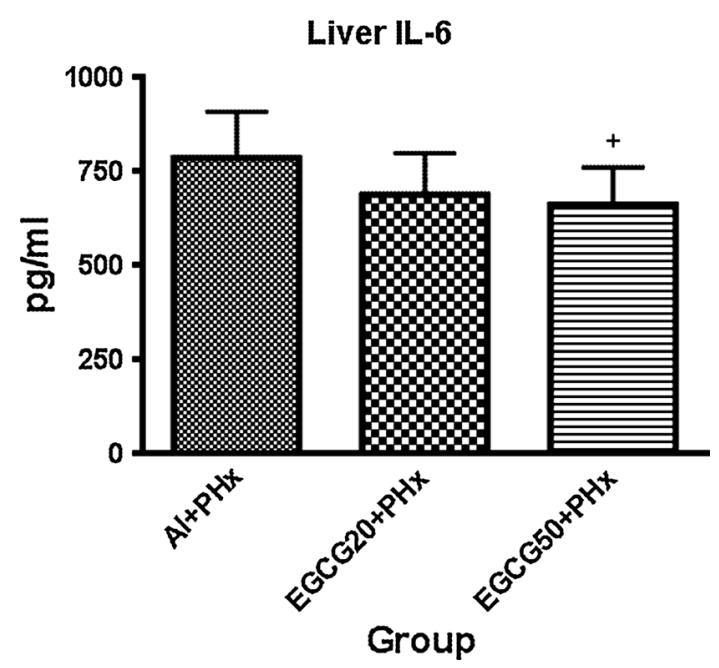

Fig. 3 Tissue levels of IL-6. ${ }^{+},{ }^{++},{ }^{+++}$When compared to the $\mathrm{AI}+\mathrm{PHx}$ group, $p<0.05 ; p<0.01 ; p<0.001$, respectively

to the $\mathrm{AI}+\mathrm{PHx}$ group. A similar trend was observed with IL-6, and its expression was significantly lower in the EGCG50 + PHx group when compared to the AI + PHx group (Fig. 3). We did not observe differences in the expression of liver TGF- $\beta 1$.

A similar non-significant trend of lower tissue MDA, GSH and GSSG content as well as lower plasmatic MDA was observed in the EGCG20 + PHx group when compared to the $\mathrm{AI}+\mathrm{PHx}$ and EGCG50 + $\mathrm{PHx}$ groups; however, none of these reached the level of statistical significance (Table 3).

Nqo-1 and HO-1 Gene Expression at the mRNA Level

There were no significant differences among hepatectomized groups in mRNA expression of Nqo-1 and HO-1. Because of the small amount of measured samples in experimental groups $(n=3)$, we observed only an insignificant trend of lower HO-1 expression in EGCG20 + PHx and higher HO-1 expression in the 
Table 3 Cytokines TNF- $\alpha$, IL-6 and TGF- $\beta$ : markers of oxidative stress

\begin{tabular}{lcccc}
\hline & AI + PHx & EGCG 20 + PHx & EGCG 50+ PHx & $p$ value \\
\hline Plasmatic MDA $(\mu \mathrm{mol} / \mathrm{l})$ & $1.20 \pm 0.18$ & $1.07 \pm 0.18$ & $1.24 \pm 0.14$ & $0.47 \pm 0.13$ \\
Tissue MDA $(\mathrm{nmol} / \mathrm{mg}$ protein) & $0.35 \pm 0.20$ & $0.27 \pm 0.07$ & $781 \pm 144$ & $\mathrm{~ns}$ \\
Tissue GSH $(\mu \mathrm{mol} / \mathrm{l})$ & $810 \pm 195$ & $717 \pm 164$ & $241 \pm 164$ & $\mathrm{~ns}$ \\
Tissue GSSG $(\mu \mathrm{mol} / \mathrm{l})$ & $238 \pm 169$ & $188 \pm 140$ & $752 \pm 126$ & $660 \pm 99^{+}$ \\
Tissue TNF- $\alpha(\mathrm{pg} / \mathrm{ml})$ & $803 \pm 103$ & $686 \pm 111$ & $\mathrm{~ns}$ \\
Tissue IL-6 $(\mathrm{pg} / \mathrm{ml})$ & $785 \pm 122$ & $6,340 \pm 4,053$ & $7,647 \pm 4,651$ & $\mathrm{~ns}$ \\
Tissue TGF- $\beta 1(\mathrm{pg} / \mathrm{ml})$ & $8,024 \pm 4,775$ & $\mathrm{~ns}$ \\
\hline
\end{tabular}

,,++++++ When comparing the EGCG50 + PHx with the AI + PHx group, $p<0.05 ; p<0.01 ; p<0.001$, respectively

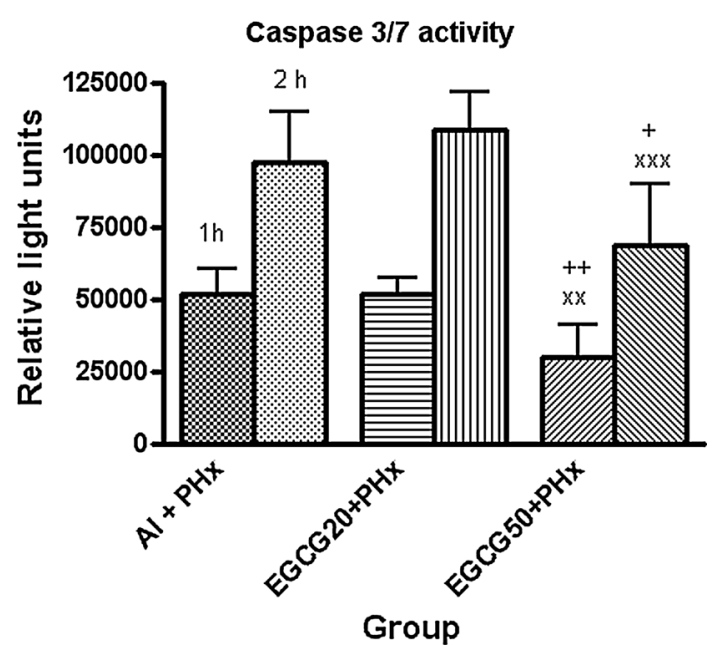

Fig. 4 Activity of executive caspases 3/7; incubation for 1 and $2 \mathrm{~h}$, respectively. ${ }^{+,++,+++}$When compared to the $\mathrm{AI}+\mathrm{PHx}$ group; ${ }^{\times}$, $\times \times, \times \times \times$ when compared to the EGCG20 + PHx group, $p<0.05$; $p<0.01 ; p<0.001$, respectively

EGCG50 + PHx group when compared to the AI + PHx group (not shown).

\section{Activity of Caspases 3/7}

After $1 \mathrm{~h}$ incubation, lower activity in the EGCG50 + PHx group was observed when compared to the $\mathrm{AI}+\mathrm{PHx}$ and EGCG20 + PHx groups ( $p<0.01$ for both comparisons). After $2 \mathrm{~h}$ incubation, the EGCG50 + PHx group also had lower activity compared to both the $\mathrm{AI}+\mathrm{PHx}(p<0.05)$ and EGCG20 + PHx ( $p<0.001)$ groups (Fig. 4).

\section{Protein Expression of Cell-Cycle Regulating Proteins}

Protein expression of p21 and p-p27 did not differ among hepatectomized groups. On the other hand, expression of p-p53 protein appeared higher in group IV $($ EGCG20 + PHx) and lower in group V (EGCG50 + PHx) than in group III (AI + PHx) (Fig. 5). We were not able to detect Bcl-2 protein.

\section{Discussion}

Despite several studies describing the beneficial effect of EGCG on the liver in various experimental models, there was no beneficial effect on liver regeneration after $\mathrm{PHx}$ in our experiment. There was even lower DNA synthesis in animals receiving higher doses of EGCG. Based on our results, the use of EGCG in conditions of organ alteration, such as regenerating liver, cannot be recommended. The effect of EGCG is complex: several hundred EGCG-regulated genes were identified in a study with microarrays [37]. Furthermore, anti-proliferative and -cancer properties of EGCG are known [38, 39].

Since EGCG was reported to decrease the production of TNF- $\alpha$ [40] and IL-6 [38], which plays an important role in liver regeneration [41, 42], we wondered if the inhibiting effect of EGCG on DNA synthesis was mediated in this way. There was only a non-significant trend of lower TNF- $\alpha$ levels in EGCG-treated hepatectomized animals when compared to hepatectomized animals receiving water for injections. A possible explanation is that $\mathrm{TNF}-\alpha$ is involved in regulation of even earlier events in liver regeneration [24]. Similarly, the levels of IL-6 were lower in the EGCG50 + PHx group compared to the $\mathrm{AI}+\mathrm{PHx}$ group.

Furthermore, EGCG was repeatedly reported to activate caspases and increase apoptosis [43-46]. Surprisingly, we found rather lower activity of executive caspases $3 / 7$ in liver homogenates from group V (EGCG50 + PHx) than from animals receiving a lower dose (EGCG20 + PHx) or vehicle only $(\mathrm{AI}+\mathrm{PHx})$. An explanation could be the different effects of EGCG on tumor and normal cells: EGCG was shown to protect hepatocytes from apoptosis caused by toxic injury $[47,48]$. Direct inhibition of caspase 3 by EGCG was also described [49]. We were not able to detect the Bcl-2 protein using Western blot. However, we are not the first workplace to fail to do so: Tzung et al. [50] reported undetectable levels of Bcl-2 mRNA and protein at $24 \mathrm{~h}$ after PHx. Our results of apoptotic body count are also in accord with [50], since the authors showed a peak of 
Fig. 5 Western blot bands of p-p53 protein with beta-actin as a loading control (p21 and p-p27 are not shown as no differences were observed)
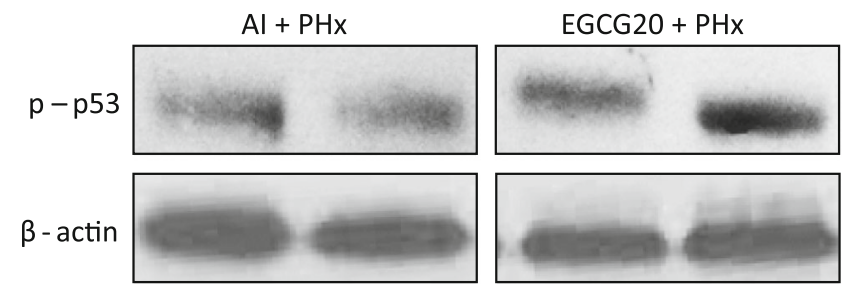

high proapoptotic Bad and rather lower expression of antiapoptotic Bcl-x at $24 \mathrm{~h}$ after PHx.

Other antiproliferative mechanisms of EGCG are changes in cell-cycle regulating proteins, especially induction of cyclin-dependent kinase inhibitors p21 and p27 [43, 51, 52], and increased expression and serine phosphorylation of p53 [45, 53]. However, we were not able to prove a difference in p21 and p27 expression among hepatectomized groups. Expressions of phosphorylated p53 appeared higher in the EGCG20 + PHx group and surprisingly lower in hepatectomized animals receiving a higher dose of EGCG (EGCG50 + PHx) when compared to the group receiving vehicle (AI $+\mathrm{PHx})$.

Many more antiproliferative mechanisms of EGCG were described, changes in protein kinases, growth factors and transcription factors [38], e.g., inhibition of NF-KB [54].

To check whether the Nrf2 pathway had been activated, we measured the expression of HO- 1 and Nqo-1 genes, which belong to Nrf2 effectors, at the mRNA level [55, 56]. However, due to the small number of samples, we were not able to prove activation of this pathway.

Interestingly, EGCG led to higher glycemia compared to vehicle-treated rats, which is in contrary to other findings $[22,23]$. It should be mentioned that orally administered EGCG decreases glucose absorption from the intestine, but parenterally administered EGCG hinders glucose uptake into the tissues [57].

Although some antioxidants accelerated liver regeneration after PHx, as could be seen in a study with vitamin C and E [11], and a study with bicyclol [58], other antioxidants and hepatoprotective agents revealed a rather inhibitory effect on liver regeneration after $\mathrm{PHx}$, namely resveratrol [59], curcumin [60] and $S$-adenosylmethionin [61]. Considering the often complex effect of natural antioxidants on cells, the diversity of the results is not surprising. Similarly, the immunosuppressant sirolimus was able to attenuate ischemia-reperfusion injury, but impaired liver regeneration after PHx [62].

Not only our results, but also other studies suggest that EGCG should be used with caution. EGCG is present in overthe-counter extracts from green tea $[63,64]$ and even in other herbal dietary supplements that do not indicate content of catechins [65]. These supplements are not without a riskthere were repeatedly reported cases of acute liver injury caused by green tea extracts [66-68]. Although these injuries can be partly explained by toxicity of other substances in the supplements (especially caffeine and/or undetected contaminants), EGCG itself also revealed important effects, particularly interaction with other drugs $[69,70]$ and a prooxidant effect at high doses [67, 71]. In mice, the dose of $120 \mathrm{mg} / \mathrm{kg}$ administered intraperitoneally was hepatotoxic and the dose $150 \mathrm{mg} / \mathrm{kg}$ lethal for all mice [71]; the dose of $1,500 \mathrm{mg} / \mathrm{kg}$ via a gastric tube was lethal for $85 \%$ of mice [64]. In rats, the dose of $2,000 \mathrm{mg} / \mathrm{kg}$ administered via a gastric tube was lethal. Recently, a cholestatic effect of EGCG was described [72]; higher levels of conjugated bilirubin (even though not significantly) in EGCG-treated animals in our study correspond to these findings.

In a study with healthy human volunteers, a single dose of 1,600 mg EGCG taken orally was found to be safe and well tolerated [73]. Potential application of EGCG in clinical studies is complicated by hardly predictable bioavailability [74].

In conclusion, administration of EGCG did not enhance the early phase of liver regeneration after PHx in rats. The higher dose even led to lower DNA synthesis. Although the tests carried out have failed to clarify the mechanism of this effect, it was probably mediated by some pathway other than $\mathrm{p} 53$.

Acknowledgments We would like to thank to Mr. Rajiv Mandalia, MD, for language review. Thanks to Miroslav Podhola, MD, PhD, for histopathological evaluation. Also thanks to Monika Pospisilova and Hana Lastuvkova for their help with PCR, and to Dr. Tomáš Roušar and Dr. René Endlicher for glutathione measurement. This work was supported by grants from Charles University in Prague, GA UK 668512, PRVOUK P37/02 and SVV-2013-266901.

\section{Conflict of interest None.}

Open Access This article is distributed under the terms of the Creative Commons Attribution Noncommercial License which permits any noncommercial use, distribution, and reproduction in any medium, provided the original author(s) and the source are credited.

\section{References}

1. Llovet JM, Di Bisceglie AM, Bruix J, et al. Panel of experts in HCC-design clinical Trials. Design and endpoints of clinical trials in hepatocellular carcinoma. $J$ Natl Cancer Inst. 2008;21:698-711. 
2. Bramhall SR, Gur U, Coldham C, et al. Liver resection for colorectal metastases. Ann R Coll Surg Engl. 2003;85:334-339.

3. Bahde R, Spiegel HU. Hepatic ischaemia-reperfusion injury from bench to bedside. Br J Surg. 2010;97:1461-1475.

4. Francés D, Ronco MT, Ochoa E, et al. Oxidative stress in primary culture hepatocytes isolated from partially hepatectomized rats. Can J Physiol Pharmacol. 2007;85:1047-1051.

5. Han SY, Chang EJ, Choi HJ, et al. Total antioxidant status and oxygen free radicals during hepatic regeneration. Transpl Proc. 2006;38:2214-2215.

6. Abu-Amara M, Gurusamy K, Hori S, Glantzounis G, Fuller B, Davidson BR. Systematic review of randomized controlled trials of pharmacological interventions to reduce ischaemia-reperfusion injury in elective liver resection with vascular occlusion. $H P B$ (Oxford). 2010;12:4-14.

7. Higgins GM, Anderson RM. Experimental pathology of the liver. I. Restoration of the liver of the white rat following partial surgical removal. Arch Pathol. 1931;12:186-202.

8. Beyer TA, Xu W, Teupser D, et al. Impaired liver regeneration in Nrf2 knockout mice: role of ROS-mediated insulin/IGF-1 resistance. EMBO J. 2008;27:212-223.

9. Surh YJ, Kundu JK, Na HK. Nrf2 as a master redox switch in turning on the cellular signaling involved in the induction of cytoprotective genes by some chemopreventive phytochemicals. Planta Med. 2008;74:1526-1539. doi:10.1055/s-0028-1088302.

10. Jung KA, Kwak MK. The Nrf2 system as a potential target for the development of indirect antioxidants. Molecules. 2010;15:7266-7291.

11. Ronco MT, deAlvarez ML, Monti J, et al. Modulation of balance between apoptosis and proliferation by lipid peroxidation (LPO) during rat liver regeneration. Mol Med. 2002;8:808-817.

12. Dinkova-Kostova AT, Talalay P. Direct and indirect antioxidant properties of inducers of cytoprotective proteins. Mol Nutr Food Res. 2008;52:S128-S138.

13. Lambert JD, Elias RJ. The antioxidant and pro-oxidant activities of green tea polyphenols: a role in cancer prevention. Arch Biochem Biophys. 2010;501:65-72. doi:10.1016/j.abb.2010.06. 013.

14. Chen C, Yu R, Owuor ED, Kong AN. Activation of antioxidantresponse element (ARE), mitogen-activated protein kinases (MAPKs) and caspases by major green tea polyphenol components during cell survival and death. Arch Pharm Res. 2000;23:605-612.

15. Chen JH, Tipoe GL, Liong EC, et al. Green tea polyphenols prevent toxin-induced hepatotoxicity in mice by down-regulating inducible nitric oxide-derived prooxidants. Am J Clin Nutr. 2004;80:742-751.

16. Yasuda Y, Shimizu M, Sakai H, et al. (-)-Epigallocatechin gallate prevents carbon tetrachloride-induced rat hepatic fibrosis by inhibiting the expression of the PDGFR $\beta$ and IGF-1R. Chem Biol Interact. 2009;10:159-164.

17. Tipoe GL, Leung TM, Liong EC, Lau TY, Fung ML, Nanji AA. Epigallocatechin-3-gallate (EGCG) reduces liver inflammation, oxidative stress and fibrosis in carbon tetrachloride (CCl4) induced liver injury in mice. Toxicology. 2010;29:45-52.

18. Fiorini RN, Donovan JL, Rodwell D, et al. Short-term administration of (-)-epigallocatechin gallate reduces hepatic steatosis and protects against warm hepatic ischemia/reperfusion injury in steatotic mice. Liver Transpl. 2005;11:298-308.

19. Kuzu N, Bahcecioglu IH, Dagli AF, Ozercan IH, Ustündag B, Sahin K. Epigallocatechin gallate attenuates experimental nonalcoholic steatohepatitis induced by high fat diet. $J$ Gastroenterol Hepatol. 2008;23:e465-e470.

20. Chung MY, Park HJ, Manautou JE, Koo SI, Bruno RS. Green tea extract protects against nonalcoholic steatohepatitis in ob/ob mice by decreasing oxidative and nitrative stress responses induced by proinflammatory enzymes. J Nutr Biochem. 2012;23:361-367. doi:10.1016/j.jnutbio.2011.01.001.

21. Giakoustidis DE, Giakoustidis AE, Iliadis S, et al. Attenuation of liver ischemia/reperfusion induced apoptosis by epigallocatechin3-gallate via down-regulation of NF-kappaB and c-Jun expression. J Surg Res. 2010;159:720-728.

22. Wolfram S, Raederstorff D, Preller M, et al. Epigallocatechin gallate supplementation alleviates diabetes in rodents. $J$ Nutr. 2006;136:2512-2518.

23. Collins QF, Liu HY, Pi J, Liu Z, Quon MJ, Cao W. Epigallocatechin-3-gallate (EGCG), a green tea polyphenol, suppresses hepatic gluconeogenesis through $5^{\prime}$-AMP-activated protein kinase. J Biol Chem. 2007;12:30143-30149.

24. Michalopoulos GK. Liver regeneration. J Cell Physiol. 2007;213:286-300.

25. Selzner M, Clavien PA. Failure of regeneration of the steatotic rat liver: disruption at two different levels in the regeneration pathway. Hepatology. 2000;31:35-42.

26. Murata H, Yagi T, Iwagaki H, et al. Mechanism of impaired regeneration of fatty liver in mouse partial hepatectomy model. $J$ Gastroenterol Hepatol. 2007;22:2173-2180.

27. Hissin PJ, Hilf R. A fluorometric method for determination of oxidized and reduced glutathione in tissues. Anal Biochem. 1976;74:214-226.

28. Roušar T, Kučera $O$, Lotková $H$, Cervinková Z. Assessment of reduced glutathione: comparison of an optimized fluorometric assay with enzymatic recycling method. Anal Biochem. 2012;423:236-240. doi:10.1016/j.ab.2012.01.030.

29. Bradford MM. A rapid and sensitive method for the quantitation of microgram quantities of protein utilizing the principle of protein-dye binding. Anal Biochem. 1976;72:248-254.

30. Ohkawa H, Ohishi N, Yagi K. Assay for lipid peroxides in animal tissues by thiobarbituric acid reaction. Anal Biochem. 1979;95:351-358.

31. Liu D, Li C, Chen Y, et al. Nuclear import of proinflammatory transcription factors is required for massive liver apoptosis induced by bacterial lipopolysaccharide. $J$ Biol Chem. 2004;279:48434-48442.

32. Seifrtová M, Havelek R, Cmielová J, et al. The response of human ectomesenchymal dental pulp stem cells to cisplatin treatment. Int Endod J. 2012;45:401-412. doi:10.1111/j.13652591.2011.01990.x.

33. Hirsova P, Kolouchova G, Dolezelova E, et al. Epigallocatechin gallate enhances biliary cholesterol secretion in healthy rats and lowers plasma and liver cholesterol in ethinylestradiol-treated rats. Eur J Pharmacol. 2012;691:38-45. doi:10.1016/j.ejphar. 2012.06.034.

34. Seabra AL, Savassi-Rocha PR, Vasconcelos AC, Lima AS, Rodrigues $\mathrm{KC}$, Almeida HM. Ischemia/reperfusion injury after continuous or intermittent hepatic pedicle clamping in rabbits. Arq Bras Cir Dig. 2012;25:105-109.

35. Bader A, Pavlica S, Deiwick A, et al. Proteomic analysis to display the effect of low doses of erythropoietin on rat liver regeneration. Life Sci. 2011;89:827-833. doi:10.1016/j.lfs.2011. 08.002.

36. Murray AB, Strecker W, Silz S. Ultrastructural changes in rat hepatocytes after partial hepatectomy, and comparison with biochemical results. J Cell Sci. 1981;50:433-448.

37. Shen G, Xu C, Hu R, et al. Comparison of (-)-epigallocatechin3 -gallate elicited liver and small intestine gene expression profiles between C57BL/6 J mice and C57BL/6 J/Nrf2 (-/-) mice. Pharm Res. 2005;22:1805-1820.

38. Singh BN, Shankar S, Srivastava RK. Green tea catechin, epigallocatechin-3-gallate (EGCG): mechanisms, perspectives and clinical applications. Biochem Pharmacol. 2011;82:1807-1821. doi:10.1016/j.bcp.2011.07.093. 
39. Yang CS, Wang X. Green tea and cancer prevention. Nutr Cancer. 2010;62:931-937. doi:10.1080/01635581.2010.509536.

40. Yang F, de Villiers WJ, McClain CJ, Varilek GW. Green tea polyphenols block endotoxin-induced tumor necrosis factor-production and lethality in a murine model. $J$ Nutr. 1998;128:2334-2340.

41. Yamada Y, Kirillova I, Peschon JJ, Fausto N. Initiation of liver growth by tumor necrosis factor: deficient liver regeneration in mice lacking type I tumor necrosis factor receptor. Proc Natl Acad Sci USA. 1997;94:1441-1446.

42. Michalopoulos GK. Liver regeneration after partial hepatectomy: critical analysis of mechanistic dilemmas. Am J Pathol. 2010;176:2-13. doi:10.2353/ajpath.2010.090675.

43. Smith DM, Wang Z, Kazi A, Li LH, Chan TH, Dou QP. Synthetic analogs of green tea polyphenols as proteasome inhibitors. Mol Med. 2002;8:382-392.

44. Gupta S, Hastak K, Afaq F, Ahmad N, Mukhtar H. Essential role of caspases in epigallocatechin-3-gallate-mediated inhibition of nuclear factor kappa B and induction of apoptosis. Oncogene. 2004;23:2507-2522.

45. Roy AM, Baliga MS, Katiyar SK. Epigallocatechin-3-gallate induces apoptosis in estrogen receptor-negative human breast carcinoma cells via modulation in protein expression of p53 and Bax and caspase-3 activation. Mol Cancer Ther. 2005;4:81-90.

46. Shankar S, Suthakar G, Srivastava RK. Epigallocatechin-3-gallate inhibits cell cycle and induces apoptosis in pancreatic cancer. Front Biosci. 2007;12:5039-5051.

47. Kagaya N, Tagawa Y, Nagashima H, Saijo R, Kawase M, Yagi K. Suppression of cytotoxin-induced cell death in isolated hepatocytes by tea catechins. Eur J Pharmacol. 2002;450:231-236.

48. Wang Y, Mei Y, Feng D, Xu L. (-)-Epigallocatechin-3-gallate protects mice from concanavalin A-induced hepatitis through suppressing immune-mediated liver injury. Clin Exp Immunol. 2006; $145: 485-492$.

49. Katunuma N, Murata E, Le QT, Hayashi Y, Ohashi A. New apoptosis cascade mediated by lysosomal enzyme and its protection by epigallo-catechin gallate. Adv Enzyme Regul. 2004:44:1-10.

50. Tzung SP, Fausto N, Hockenbery DM. Expression of Bcl-2 family during liver regeneration and identification of $\mathrm{Bcl}-\mathrm{x}$ as a delayed early response gene. Am J Pathol. 1997;150:1985-1995.

51. Gupta S, Hussain T, Mukhtar H. Molecular pathway for (-)epigallocatechin-3-gallate-induced cell cycle arrest and apoptosis of human prostate carcinoma cells. Arch Biochem Biophys. 2003;410:177-185.

52. Liang YC, Lin-Shiau SY, Chen CF, Lin JK. Inhibition of cyclindependent kinases 2 and 4 activities as well as induction of $\mathrm{Cdk}$ inhibitors p21 and p27 during growth arrest of human breast carcinoma cells by (-)-epigallocatechin-3-gallate. J Cell Biochem. 1999;75:1-12.

53. Hastak K, Gupta S, Ahmad N, Agarwal MK, Agarwal ML, Mukhtar H. Role of p53 and NF-kappaB in epigallocatechin-3gallate-induced apoptosis of $\mathrm{LNCaP}$ cells. Oncogene. 2003;22:4851-4859.

54. Yang F, Oz HS, Barve S, de Villiers WJ, McClain CJ, Varilek GW. The green tea polyphenol (-)-epigallocatechin-3-gallate blocks nuclear factor-kappa B activation by inhibiting I kappa B kinase activity in the intestinal epithelial cell line IEC-6. Mol Pharmacol. 2001;60:528-533.

55. Wu CC, Hsu MC, Hsieh CW, Lin JB, Lai PH, Wung BS. Upregulation of heme oxygenase-1 by epigallocatechin-3-gallate via the phosphatidylinositol 3-kinase/Akt and ERK pathways. Life Sci. 2006;78:2889-2897.
56. Sahin K, Tuzcu M, Gencoglu H, et al. Epigallocatechin-3-gallate activates Nrf2/HO-1 signaling pathway in cisplatin-induced nephrotoxicity in rats. Life Sci. 2010;87:240-245. doi:10.1016/j. lfs.2010.06.014.

57. Park JH, Jin JY, Baek WK, et al. Ambivalent role of gallated catechins in glucose tolerance in humans: a novel insight into non-absorbable gallated catechin-derived inhibitors of glucose absorption. J Physiol Pharmacol. 2009;60:101-109.

58. Yao XM, Zhao J, Li Y, Li Y. Effects of bicyclol on liver regeneration after partial hepatectomy in rats. Dig Dis Sci. 2009;54:774-781. doi:10.1007/s10620-009-0715-6.

59. Kirimlioglu H, Ecevit A, Yilmaz S, Kirimlioglu V, Karabulut AB. Effect of resveratrol and melatonin on oxidative stress enzymes, regeneration, and hepatocyte ultrastructure in rats subjected to $70 \%$ partial hepatectomy. Transpl Proc. 2008;40:285-289.

60. Seehofer D, Schirmeier A, Bengmark S, et al. Inhibitory effect of curcumin on early liver regeneration following partial hepatectomy in rats. J Surg Res. 2009;155:195-200.

61. Kohoutek L, Cervinková Z, Kucera O, et al. Effect of S-adenosylmethionine on liver regeneration induced by partial hepatectomy. Gen Physiol Biophys. 2010;29:72-78.

62. Liu YX, Jin LM, Zhou L. Sirolimus attenuates reduced-size liver ischemia-reperfusion injury but impairs liver regeneration in rats. Dig Dis Sci. 2010;55:2255-2262. doi:10.1007/s10620-009-1002-2.

63. Isbrucker RA, Edwards JA, Wolz E, Davidovich A, Bausch J. Safety studies on epigallocatechin gallate (EGCG) preparations. Part 2: dermal, acute and short-term toxicity studies. Food Chem Toxicol. 2006;44:636-650.

64. Lambert JD, Kennett MJ, Sang S, Reuhl KR, Ju J, Yang CS. Hepatotoxicity of high oral dose (-)-epigallocatechin-3-gallate in mice. Food Chem Toxicol. 2010;48:409-416. doi:10.1016/j.fct. 2009.10.030.

65. Navarro VJ, Bonkovsky HL, Hwang SI, Vega M, Barnhart H, Serrano J. Catechins in dietary supplements and hepatotoxicity. Dig Dis Sci. 2013;58:2682-2690. doi:10.1007/s10620-013-2687-9.

66. Molinari M, Watt KD, Kruszyna T, et al. Acute liver failure induced by green tea extracts: case report and review of the literature. Liver Transpl. 2006;12:1892-1895.

67. Mazzanti G, Menniti-Ippolito F, Moro PA, et al. Hepatotoxicity from green tea: a review of the literature and two unpublished cases. Eur J Clin Pharmacol. 2009;65:331-341.

68. Chen GC, Ramanathan VS, Law D, et al. Acute liver injury induced by weight-loss herbal supplements. World J Hepatol. 2010;2:410-415.

69. Shim M, Saab S. Severe hepatotoxicity due to hydroxycut: a case report. Dig Dis Sci. 2009;54:406-408. doi:10.1007/s10620-0080353-4.

70. Schönthal AH. Adverse effects of concentrated green tea extracts. Mol Nutr Food Res. 2011;55:874-885.

71. Galati G, Lin A, Sultan AM, O'Brien PJ. Cellular and in vivo hepatotoxicity caused by green tea phenolic acids and catechins. Free Radic Biol Med. 2006;40:570-580.

72. Hirsova P, Karlasova G, Dolezelova E, et al. Cholestatic effect of epigallocatechin gallate in rats is mediated via decreased expression of Mrp2. Toxicology. 2013;303:9-15. doi:10.1016/j. tox.2012.10.018.

73. Ullmann U, Haller J, Decourt JP, et al. A single ascending dose study of epigallocatechin gallate in healthy volunteers. J Int Med Res. 2003;31:88-101.

74. Mereles D, Hunstein W. Epigallocatechin-3-gallate (EGCG) for clinical trials: more pitfalls than promises? Int $\mathrm{J} \mathrm{Mol}$ Sci. 2011;12:5592-5603. 